\title{
Correction to: The prevalence of obstructive sleep apnea in interstitial lung disease: a systematic review and meta-analysis
}

\author{
Yang Cheng ${ }^{1} \cdot$ Yan Wang ${ }^{1} \cdot$ Li Dai $^{1}$ \\ Published online: 23 March 2021 \\ (C) Springer Nature Switzerland AG 2021
}

\section{Correction to: Sleep and Breathing}

https://doi.org/10.1007/s11325-020-02282-Z

In the originally published article, the first names and last names of authors were presented in the wrong order. The names Cheng Yang, Wang Yan, and Dai Li should be presented as Yang Cheng, Yan Wang, Li Dai. These are now correctly presented above.

The original article has been corrected.

Publisher's note Springer Nature remains neutral with regard to jurisdictional claims in published maps and institutional affiliations.

The online version of the original article can be found at https://oi.org/ $10.1007 / \mathrm{s} 11325-020-02282-\mathrm{Z}$

Yang Cheng

chengyang0323@outlook.com

1 Department of Respiratory and Critical Care Medicine, Beijing Jishuitan Hospital, The Fourth Medical College of Peking University, No. 31, Xinjiekou East Street, Beijing 100035, China 